\title{
LOS DEVENIRES MINORITARIOS EN LOS CUENTOS DE CLARICE LISPECTOR: CONDICIONES DE UNA CARTOGRAFÍA DESEANTE
}

\author{
Camila Roccatagliata*
}

\section{Resumen}

Gilles Deleuze y Félix Guattari en su Kafka. Por una literatura menor atribuyen a una literatura menor tres características fundamentales: el uso minoritorio de una lengua mayor, el carácter social y político por sobre el individual en el texto y el valor colectivo de la obra. El propósito del presente trabajo consiste en ver de qué manera esas características se conjugan en los cuentos de Clarice Lispector para obtener como resultado un recorrido por el Brasil minoritario y deseante.

\section{Palabras claves}

literatura menor - devenir minoritario - nomadismo - deseo - rizoma

\section{MINORITIES BECOMING IN CLARICE LISPECTOR'S SHORT STORIES: A MAPPING OF DESIRE}

\begin{abstract}
Gilles Deleuze and Félix Guattari in their Kafka: toward a minor literature propose three main features for a minor literature: the minoritary use of a major language, the social and political nature over the individual one in the text, and the collective value taken on by the work. This paper consists in trying to unveil the way in which these features are combined in Clarice Lispector's short stories and, as a result of this, setting out to examine the Brazil of minorities and wishes.
\end{abstract}

Keywords: minor literature - becoming minority - nomadism - desire - rhizome

*Camila Roccatagliata es Profesora en Castellano, Literatura y Latín y maestranda en literatura española y latinoamericana por la Universidad de Buenos Aires. Se desempeña como docente en nivel medio y superior y actualmente realiza una investigación sobre Sida y literatura latinoamericana. E-mail: camirocca@gmail.com 
La hipótesis del siguiente artículo es que la literatura de Clarice Lispector puede considerarse una literatura menor ${ }^{1}$, característica que le permite plasmar en sus textos las vicisitudes, contrariedades, los deseos y anhelos de distintas minorías excluidas o relegadas de la sociedad imperante (detallaré en el transcurrir del trabajo qué minorías son las que Lispector pincela con tanta genialidad y originalidad).

Me propongo, a tal fin, analizar algunos de los cuentos de Clarice Lispector desde los siguientes conceptos teóricos de Gilles Deleuze y Félix Guattari:

- devenir minoritario, devenir mujer, devenir animal;

- $\quad$ nomadismo;

- $\quad$ rizoma;

- mapa;

- $\quad$ líneas de fuga.

Además, tendré en cuenta un análisis que hace Earl Fitz sobre la relación entre la teoría posestructuralista y la literatura de Lispector para desentrañar esa peculiar relación.

También tomaré algunos de los ensayos del escritor argentino Néstor Perlongher porque tienen la peculiaridad de relacionar la teoría deleuziana con el universo deseante del Brasil, país en el que se exilia y en el que produce gran parte de su corpus teórico y literario. Estos ensayos me servirán como herramientas para dar cuenta de ese universo tan atrayente y a la vez complejo que aparece en los cuentos de Lispector.

Asimismo, me apoyaré en los conceptos de rango axiológico y de relaciones de proximidad entre autor/héroe/lector de Valentín Voloshinov para poder analizar la importancia que se le da a las distintas voces protagonistas de los cuentos y para ver cómo, a través de la forma y de esa particular relación, Lispector retrata la diversidad social, genérica, cultural, política, de Brasil.

1 Más adelante desarrollaré el concepto de literatura menor desde la perspectiva de Gilles Deleuze y Félix Guattari. 
Erigiendo la figura de una conciencia universal minoritaria, uno se dirige a potencias de devenir que pertenecen a otro dominio que el Poder y la Dominación. Gilles Deleuze y Félix Guattari

Como ya anticipé, tomaré de la obra de Clarice Lispector una selección de cuentos $^{2}$, a saber: "Devaneo y embriaguez de una muchacha", "Las aguas del mundo", "Encarnación involuntaria", "El huevo y la gallina", "La salida del tren", "Miss Algrave”, "Plaza Mauá”, y “¿Dónde estuviste de noche?”. La selección no responde a una lógica común y unitaria, más bien se construye como un mapa $^{3}$ de acuerdo a distinto aspectos: temas, personajes, minorías retratadas, relación entre los significantes, etc. La idea es entrar y salir de los textos, conectándolos continuamente; zambullirse en estos relatos a través de sus múltiples y diversas entradas.

Llegado este punto, me parece indispensable intentar definir qué es una literatura menor para Deleuze y Guattari. En Kafka. Por una literatura menor (1978) estos autores dan tres "características" " por las que uno podría llegar a reconocer una literatura menor. La primera sería el uso que una minoría hace de una lengua mayor; ese uso estaría signado por su carácter desterritorializante, en tanto desterritorializar implica, asimismo, correrse de lo estratificado, organizado, atribuido y ese correrse implicaría un devenir, diversificar, abrir el significante al infinito, salirse del centro etc. En sus propios términos:

Una literatura menor no es la literatura de un idioma menor, sino la literatura que una minoría hace dentro de una lengua mayor. De cualquier modo, su primera característica es que, en ese caso, el idioma se ve afectado por un fuerte coeficiente de desterritorialización. (DELEUZE; GUITTARI, 1997, p. 28)

2 La edición en español que utilizaré para citar los cuentos de Lispector es la siguiente: Lispector, Clarice (2008), Cuentos reunidos, Madrid, Siruela.

3 "Contrariamente al grafismo, al dibujo o a la fotografía, contrariamente a los calcos, el rizoma está relacionado con un mapa que debe ser producido, construido, siempre desmontable, conectable, alterable, modificable, con múltiples entradas y salidas, con sus líneas de fuga" (DELEUZE; GUATTARI, 1997, p. 49).

4 El entrecomillado se debe a que este tipo de conceptos son un tanto espinosos para con la concepción de estos autores en tanto y en cuanto ellos proclaman deshacerse de toda categoría, estructura o concepto que delimite, determine u oriente el análisis hacia sentidos unívocos y arborescentes. 
La segunda característica estaría signada por el hecho de que, en las literaturas menores, todo es político en la medida que el carácter individual no es lo importante sino más bien el carácter social:

La segunda característica de las literaturas menores es que en ellas todo es político. En las "grandes" literaturas, por el contrario, el problema individual (familiar, conyugal, etcétera) tiende a unirse con otros problemas no menos individuales, dejando el medio social como una especie de ambiente o de trasfondo [...] La literatura menor es completamente diferente: su espacio reducido hace que cada problema individual se conecte de inmediato con la política. (DELEUZE; GUATTARI, 1997, p. 29)

La tercera y última sostiene que en este tipo de literaturas todo adquiere valor colectivo. Finalmente, estas tres particularidades no serían atributo de tal o cual literatura sino "las condiciones revolucionarias de cualquier literatura en el seno de la llamada mayor (o establecida)" (DELEUZE; GUATTARI, 1997, p. 30).

Toda la tradición, el pensamiento y la ciencia occidental están construidos a partir de una coyuntura de poder y dominación, de represión y esencialismo y cualquier propuesta alternativa a lo mayoritario, lo instituido, lo naturalizado, es considerada como una provocación, una anomalía, una desviación.

Devenir múltiple, minoritario, diverso es, de este modo, una manera posible de desnaturalizar las consignas totalizantes y dogmáticas a las que estamos acostumbrados. Ese devenir implica correrse del centro en el que se instala la "lengua mayor" ligada a la mayoría. Ese devenir minoritario es lo que permite lo nómade, la variación continua, la creación, las líneas de fuga. Lo importante, sin embargo, sería no convertir lo minoritario en mayoritario (la lengua menor en lengua mayor), sino cuestionar y, en ese cuestionamiento, transformar lo mayoritario desde el margen, lo periférico, socavando sus binarismos, poniendo en duda sus consignas. Esta propuesta alternativa está ligada a la idea de "volverse extranjero en el propio país" o la de ser "bilingüe o multilingüe en la propia lengua" (1997) desde el campo literario, lingüístico, político-social, para devenir creativo, minoritario y para desterritorializar lo dominante.

Sin lugar a dudas, la obra de Lispector es un ejemplo de escritura que deviene minoritaria, que se contrapone a lo hegemónico, que desterritorializa, al valerse de lo popular, lo excéntrico, lo marginal, para cuestionar desde la forma y el contenido lo que se considera de "buen gusto", "lo correcto", lo canónico. Cruza fronteras culturales, de género, sociales, políticas, morales, logrando escabullirse de los mecanismos del poder. 
En eso consiste probablemente devenir minoritario, en encontrar los intersticios del sistema, en aflorar lo que deliberada e inconscientemente se ha escondido, en nombrar lo prohibido, en reírse de "lo serio", lo doloroso y en resignificar y revalorizar lo que el supuesto "buen gusto" descarta. Veamos entonces, cómo devienen minoritarios estos cuentos de Lispector. Tendré en cuenta, a tal fin, los conceptos teóricos de Voloshinov de rango axiológico y de relaciones de proximidad entre autor/héroe/lector para mostrar la importancia que se le asigna a las distintas voces y para ver cómo mediante la utilización de distintos recursos literarios (mediante la elección de la forma) se nos introduce en diversas visiones de mundo correspondientes a los distintos protagonistas y al sujeto de enunciación.

\title{
Una conciencia desvariada
}

\author{
Muchas mujeres modernas son así. Las \\ mujeres están obligadas a representar lo que no son \\ [...]. Están al borde de la neurosis. \\ Simone de Beavoir \\ La mujer, el más ininteligible de los seres \\ vivos. \\ Clarice Lispector
}

Valentín Voloshinov (1926) sostiene que la forma es evaluadora porque condensa las evaluaciones sociales, la ideología no expresada. Tanto la elección de las palabras como la de los procedimientos o la de los géneros nos muestran la ideología, la evaluación acerca del mundo contenida en la misma obra de arte.

Clarice Lispector elige como título del primer cuento que analizaremos la siguiente frase: "Devaneo y embriaguez de una muchacha". El primer sustantivo nos anticipa el principio constructivo de este relato: el delirio, el desconcierto. En este cuento, María Quiteria, comparte con el lector sus obsesiones, sus angustias, sus exabruptos, sus fobias, sus prejuicios, sus rencores, sus miserias. Y lo hace mediante un extenso, incoherente, catárquico y rizomático monólogo.

Una desordenada narración (“Oh, estaba muy humillada por haber ido a la tasca sin sombrero, ahora la cabeza le parecía desnuda. Y la otra, con sus aires de señora, haciéndose pasar por delicada. ¡Bien sé lo que te falta, damisela, y a tu hombre amarillo! Y si piensas que te envidio tu pecho plano, puedes ir sabiendo que no me 
importa nada, que me río de tus sombreros. A desvergonzadas como tú, haciéndose las importantes, yo las lleno de sopapos." 2008, p. 46-47), la fusión de voces y narradores (tercera y primera persona, discursos referidos, etc. $)^{5}$ y las alternancia de diversas y arbitrarias (?) marcas para introducirlas ("Estaba sentada, bien tiesa, en su casa, el estómago muy lleno, absorta, resignada, con la delicadeza de quien espera sentado que otro despierte. 'Te atiborraste de comida, ahora a pagar el pato', se dijo, melancólica, mirándose los deditos blancos del pie. Miraba alrededor, paciente, obediente. Ay, palabras, palabras, objetos de habitación alineados en orden de palabras formando aquellas frases turbias y aburridas, que quien sepa leer, leerá. Aburrimiento, aburrimiento, ay qué fastidio [...] Ay, me da una cosa tan rara que ni sé siquiera cómo explicarla." p.47-48), los cambios de tono que develan el vaivén de los contrastantes estados anímicos (“Las más santitas eran las que estaban más llenas de desvergüenza. Y el camarero, el gran estúpido, sirviéndola lleno de atenciones, el ladino: y el hombre amarillo que la acompañaba haciendo la vista gorda [...] ¿Y esta carcajada? Esa carcajada que le estaba saliendo misteriosamente de una garganta llena y blanca, en respuesta a la delicadeza del comerciante, carcajada venida de las profundidades de aquel sueño, y de la profundidad de aquella seguridad de quien tiene un cuerpo. [...] ¡Ay, qué cosa me viene, santa madre mía! Era la tristeza.” p. 45 - 46, 49): todos recursos literarios que nos transmiten y nos sumergen en un mundo tan impactante como tenebroso: la frágil frontera entre la tristeza, la depresión, la soledad y la locura.

María es víctima (¿y responsable?) de un mundo que la margina como persona, como madre, como mujer. Y reacciona frente a ese mundo hostil: contra el rol impuesto de esposa y de ama de casa ("Despertó cuando el marido ya había vuelto del trabajo y entró en la habitación. No quiso comer ni salir de sus ensoñaciones, y se durmió de nuevo: el hombre que se las arreglara con las sobras del almuerzo."- p. 42), contra todo actividad "productiva" ("Ella todavía estaba en la cama, tranquila, improvisada [...] Allí estaba en la cama, pensando, pensando, casi riendo como ante un folletín. Pensando, pensando. ¿En qué? No lo sabía. Y así se dejó estar.” - p. 43), contra los usos,

5 Robert Humphrey (1969, p. 41) denomina a este recurso "monólogo interior indirecto con pronombre de tercera persona" y define así sus características: "Un narrador omnisciente presenta un material no articulado oralmente como si proviniera directamente de la conciencia del personaje, conduciendo al lector a través de él y ayudándole con comentarios y descripciones. El narrador se interpone entre la sique del personaje y el lector como guía bien informado." 
costumbres, y "buenos modales"6 ("Y si su marido no estaba borracho era porque no quería faltarle el respeto al comerciante y, lleno de empeño y humildad, le dejaba al otro el cantar del gallo. Lo que quedaba bien para esa ocasión tan distinguida, pero le daba, al mismo tiempo, muchos deseos de reír. ¡Y desprecio! ¡Miraba al marido con su traje nuevo y le hacía una gracia! Borracha a más no poder, pero sin perder el brío de muchachita." - p. 44), contra las relaciones frívolas y poco afectivas (“Qué desprecio por las personas secas del restaurante, mientras ella estaba gorda y pesada, generosa a más no poder. Y todos tan distantes en el restaurante, separados uno del otro como si jamás uno pudiera hablar con el otro. Cada uno para sí, y Dios para todos.”- p. 46) aquí nos resuenan las crónicas de Walter Benjamin -, contra el mundo de las apariencias, de la máscara y el disfraz ("De entrada la había visto, sentada en una mesa con su hombre, toda llena de sombreros y adornos, rubia como un escudo falso, toda santurrona y fina - ¡qué lindo sombrero tenía! -, seguro que ni siquiera era casada, y ponía esa cara de santa." - p. 46), en resumidas cuenta, a todo su entorno. Pero de ese entorno, sólo sabemos lo que ella no cuenta (o lo que el narrador nos cuenta de ella).

Aquí el autor textual nos delimita un rango axiológico, una senda a recorrer: la de la mujer que sufre, que se enajena, que se busca y se critica a sí misma en ese criticar a los demás. Sin embargo, no parecería tan importante en el texto la búsqueda de venganza o la resolución de la angustia y la desesperación, sino acompañar la voz de la mujer que sufre, que desea contarnos cómo ese mundo la lastima. En este caso, las relaciones de proximidad entre autor/héroe/lector se presentan muy estrechamente. Se privilegia, por sobre todas las voces posibles, la voz de María: sólo a través de su visión conocemos su entorno y al resto de los personajes.

Y esta voz que nos deja bien en claro que "no todo lo que brilla es oro" aparece desde una doble marginalidad: marginal como mujer, en tanto y en cuanto se opone al mundo hegemónico patriarcal en todas sus expresiones, y marginal como mujer alcohólica, teniendo en cuenta todo lo que eso implica al nivel de la moral, las costumbres y hasta el nivel del discurso médico-higienista. Por supuesto, en un mundo

6 No es éste, por supuesto, el único texto en el que Clarice Lispector se ríe, critica y parodia las "buenas costumbres" de las clases privilegiadas. Es una característica que se repite también en sus crónicas ("Crónica social", "La sala de las apariciones", por citar algunas) y en sus novelas, y que tiene indudablemente que ver con su propia experiencia en el universo diplomático (Clarice era esposa del diplomático Maury Gurgel Valente, a quien acompañaría a menudo de país en país, hasta la separación en 1959. Los constantes viajes fueron uno de los conflictos de la vida de Clarice, quien seguía al marido dejando detrás familia, amigos y profesión.) 
patriarcal y machista, el uso y abuso del alcohol (y otras sustancias) se reserva y tolera sólo en y para el hombre. Cabe destacar asimismo que la introducción de esta perspectiva signada por el alcoholismo encierra de por sí una gran paradoja: por un lado, podemos considerar que todo lo que se nos dice está distorsionado por los efectos de esta sustancia; por otro, podemos considerar (apoyados en el saber popular que considera que "los locos y los borrachos" siempre dicen la verdad) que la ingesta de alcohol produce la epifanía, el develamiento, la conciencia de que este mundo hostil no la satisface, ni como madre, ni como esposa, ni como ama de casa, ni como mujer etc. ${ }^{7}$ El texto deja bien en claro que "el orden natural de las cosas" ha sido invertido:

\footnotetext{
Y cuando estaba embriagada, como una abundante comida de domingo, todo lo que por la propia naturaleza está separado -olor a aceite en un lado, hombre en otro, sopa en un lado, camarero en el otro- se unía raramente por la propia naturaleza, y todo no pasaba de ser una sirvengüenzada solamente, una bellaquería. (p. 46)
}

Y aunque aparecen ciertas frases que la juzgan (a veces frases que parece decirse ella misma, a veces frases de un narrador que la observa distante) y parezca cerrarse el relato en la tristeza (“¡Ay, qué cosa me viene, santa madre mía! Era la tristeza.” p. 49), María termina contemplando la luna y sonriendo: "Entonces la grosería explotó en súbito amor; perra, dijo riéndose” (p. 49). Ese improvisto enamoramiento, este sentirse bien consigo misma, nos abre una puerta de lectura del cuento: María se sabe incompleta, sufriente, triste, solitaria, pero también se sabe crítica, sagaz, capaz de reírse (y en ese reírse, también contraponerse) de ese universo trastocado, frívolo y enajenante.

\section{Mujeres extraordinarias, mujeres que devienen}

En "Las aguas del mundo" una mujer, en una playa solitaria, contempla el mar y su vastedad. El narrador dice que ella se desconoce y que "su osadía consiste en

7 Podemos circunscribir esta relación "ingesta de x sustancia-develamiento" en una larga tradición literaria y artística; pensemos por ejemplo en la leyenda medieval de Tristán e Isolda que narra las hazañas de un héroe que comete una grave traición por culpa de un amor forzado por un brebaje mágico; en "El Aleph" de Borges, allí Carlos Argentino Daneri le convida a Borges una copa de coñac antes de acompañarlo al sótano donde este hombre escéptico tendrá su máxima epifanía (La bebida parece ser, en este cuento, el apoyo necesario para recibir el develamiento, para percibir el infinito.) o en las bacanales griegas. Por supuesto, esta larga tradición siempre estuvo vinculada a lo pagano, a lo no sacro, a lo pecaminoso y, de este modo, opuesta a lo dominante, lo "correcto", lo "bien visto". 
continuar aunque no se conozca" (p. 293); es decir, tener el valor de seguir buscando aunque no se sepa qué. Luego se dirige hacia el mar y allí, en un ritual plagado de metáforas sexuales, se deja penetrar por él:

Y era eso lo que estaba echando de menos: el mar por dentro como el líquido espeso de un hombre. Ahora está completamente igual a sí misma [...] Vuelve a zambullirse, de nuevo bebe más agua, ahora sin voracidad pues no necesita más. Es la amante que sabe que volverá a tenerlo todo. (p. 293)

En esa inmersión, esa mujer se sumerge en una búsqueda de sí misma, de su identidad, en el sentido más amplio y más ontológico del término. Comienza a saber lo que desea y luego, al salir del agua, se siente excepcional haciendo lo que todos hacen al salir del mar (no caminar sobre las aguas, sino dentro de ellas). Y aquí estas frases tan paradójicas y tal vez irónicas de la literatura de Lispector: ella se vuelve única por no hacer lo que hizo Jesús y, sin embargo, repite lo que el hombre hizo durante toda la humanidad. Pero en ese repetirse se descubre y se sabe ahora y para siempre libre de todo peligro (¿el peligro de nunca encontrarse o conocerse a uno mismo?).

Lo cierto es que esta heroína anónima nos acerca a una característica fundamental de la obra de esta autora, una de las características por la que podríamos considerar a su literatura como una literatura menor: muchas de las mujeres que toma Clarice son mujeres que atraviesan, por distintas circunstancias, intensas y rizomáticas búsquedas, mujeres que de una forma u otra desafían lo establecido, lo predeterminado, que no son puntos sino líneas de fuga, sujetos nómades, personalidades que se metamorfosean en su constante actuar, en su constante devenir. ${ }^{8}$

De esta manera, Lispector plasma en su literatura lo que en el plano filosófico, psicológico, lingüístico, se ha estado debatiendo en las últimas décadas: la idea de identidad no esencialista vs la identidad unívoca y cristalizada. En términos de Leonor Arfuch:

\footnotetext{
${ }^{8}$ Según Deleuze y Guattari (1997) "el rizoma sólo está hecho de líneas: líneas de segmentaridad, de estratificación, como dimensiones, pero también líneas de fuga o de desterritorialización como dimensión máxima según la cual, siguiéndola, la multiplicidad se metamorfosea al cambiar de naturaleza. Pero no hay que confundir tales líneas, o lineamientos, con las filiaciones de tipo arborescente, que tan sólo son uniones localizables entre puntos y posiciones". De este modo, lo nómade se opone a lo sedentario, lo fijo, lo que depende de un centro o jerarquía. Lo múltiple, lo disperso, lo marginal, lo otro, se opone a lo Mismo, lo esencial, a una identidad superior y última.
} 
La concepción contemporánea de las identidades, a la luz del psicoanálisis, la lingüística y las teorías del discurso, se aleja de todo esencialismo -e n tanto conjunto de atributos "dados", preexistentes - para pensar más bien su cualidad relacional, contingente, su posicionalidad en una trama social de determinaciones e indeterminaciones, su desajuste - en exceso o en falta respecto de cualquier intento totalizador. [...] Lejos de configuraciones estáticas totalizadoras, lo que se pone de manifiesto es la dimensión conflictiva de toda identidad. $(2005$, p. 84$)$

De este modo, se erige una idea de identidad performativa en contraposición a una identidad sustancial o una idea de la identidad como una serie de atributos generales y universales.

En "El huevo y la gallina" una mujer observa un huevo en la cocina. Esa contemplación la lleva a una infinita red de pensamientos, de reflexiones de todo tipo, a un fluir de la conciencia que desembocará en una epifanía profana. En este cuento aparece directamente la primera persona, la voz y la conciencia de la protagonista que termina asumiendo la posición y la perspectiva de la gallina. Lispector hace de este relato un juego de perspectivas constantes, una conjugación de caóticas líneas de fuga. A una inacabable serie de oraciones breves ("El huevo es el alma de la gallina. La gallina torpe. El huevo exacto. El huevo exacto. La gallina asustada. El huevo exacto. Como un proyectil detenido. Pues huevo es huevo en el espacio." - p. 198), se le suma un discurso cuasi paranoico y conspirativo que describe un mundo repleto de agentes cuya principal función es que el huevo exista (“A todos los agentes les son dadas muchas ventajas para que el huevo se haga [...] Austeramente viven todos los placeres: inclusive es nuestro sacrificio para que el huevo se haga." - p. 203). Esos agentes, al igual que las gallinas, al igual que ella (porque ella misma sería un agente, ella misma sería una gallina) tienen una función que excede aquellas que a diario desempeñan:

El falso empleo que me dieron para disfrazar mi verdadera función, pues aprovecho el falso empleo y de él hago el verdadero [...] Pero es que nadie sabe cómo se siente por dentro aquel cuyo empleo consiste en fingir que está traicionando, y que termina creyendo en la propia traición. Cuyo empleo consiste en olvidar diariamente. (p. 204)

La autora parece querer decirnos que constantemente cumplimos los roles que nos imponen, que nos distraen de aquello que realmente es importante y de aquello que nos caracterizaría como seres humanos completos y dignos. 
De este modo, Clarice Lispector nos muestra el mundo de la mujer que deviene, que atraviesa distintos estados no para llegar a una meta fija o última, sino una mujer que se resignifica en cada uno de sus actos. Mujer capaz de cuestionar su entorno, de envolverse en la perspectiva del otro, de tomar conciencia de su ser, su identidad y su devenir. Y esa constante performatividad identitaria se une, en el universo femenino de las heroínas de Lispector al universo del deseo.

\section{Mujeres deseantes} El deseo, evidentemente, pasa por todas estas
posiciones y estos estados, o más bien, sigue todas estas
líneas: el deseo no es forma, sino un proceso, en los dos
sentidos de la palabra.

Gilles Deleuza y Félix Guattari

Un relámpago, después la noche. Fugitiva belleza cuya mirada me ha hecho súbitamente renacer eternidad?

¿es que no te voy a volver a ver más en la

Tal vez te veré lejos de aquí, o más tarde, quizás nunca más.

Pues ignoro donde tú huyes y tú no sabes a dónde yo voy.

Oh tú, a quien habría amado, oh tú, que lo supiste

Charles Baudelaire

Cierta pulsión nómade se abre paso por los intersticios de la ciudad. Estos impulsos no suelen manifestarse abiertamente a la luz del día. Es preciso buscarlos no en la centralidad resplandeciente de la urbe sino en los brillos opacos del margen.

Néstor Perlongher

Algunos textos de Clarice Lispector nos abren las puertas de un universo ligado al deseo, a lo errante, a los rincones marginales del mundo moderno. Uno de ellos es "Miss Algrave".

Desde lo paratextual, Lispector parece querer jugar con este texto, querer romper con todo parámetro de seriedad, autoridad y buena costumbre. Analicemos algunos de los epígrafes como ejemplo. El segundo tiene como autor a un "personaje mío aún sin nombre", es decir, el epígrafe tiene como fuente de autoridad un personaje de ficción que aún no tiene nombre y que, por lo tanto, aún está pensándose, construyéndose. Y este autor anónimo es quien dice conocer el cuerpo y su torbellino, 
su aspecto devaneante. Y si lo ligamos con el primer epígrafe que sostiene que lo que quiebra el alma es el deseo, podemos deducir, o por lo menos empezar a pensar, que el cuento estará de algún modo ligado al devenir deseante del cuerpo y del alma, a lo que lo vuelve pesado, grave, desconcertante, embriagante. El último epígrafe directamente "no se sabe de quién es", borra toda huella de autoridad, pero nos conduce a la idea de una historia de amor signada por la culpa y la tragedia. Cabe destacar, asimismo, que todos los epígrafes funden la idea del cuerpo con la de alma, de lo sagrado con lo profano, de lo perenne con lo eterno.

Pasemos entonces al título, la antesala del cuento propiamente dicho. Aquí Lispector podría estar experimentando con algunos sentidos que se podrían dar al mismo y que funcionarían como líneas de sentido o interpretación. Por un lado, Algarve es en Portugal una zona de prostitución, por otro, "grave” es "tumba” en inglés. ¿Por qué buscarle un sentido en inglés? Porque la autora ubica el cuento en Londres. Por supuesto, haber leído el texto nos lleva a considerar estas dos opciones, sabiendo que hay en el cuento un juego entre el estereotipo de una manera de ser muy puritana de los ingleses y una más ligada al deseo, al cuerpo, a lo pecaminoso (imaginario latinoamericano desde la percepción hegemónica eurocentrista). Una vez más lo puro y impuro, lo "correcto" y lo "incorrecto" en la literatura de Lispector.

Por fin, el cuento. Como ya dijimos anteriormente, Lispector inscribe este relato en Londres, ciudad "donde los fantasmas existen en las callejuelas oscuras". Esta referencia dada por el narrador ubica al cuento en relación con la literatura fantástica y fantasmagórica tan importante en la literatura inglesa, y en relación con aquella literatura que se pregunta por aquellos que es tan difícil de delimitar: ¿qué es real y qué es fantástico en un relato? Ruth, la protagonista de este cuento, segura de que nadie le creería, pero también de que lo que le había pasado era verdad, nunca contó su experiencia místico-profana. Pero este narrador tan cercano a la conciencia del este personaje femenino, nos revela su tan íntimo secreto.

Esta heroína tan ingenua e inocente ("Aunque la atormentaba un recuerdo horrible: cuando era pequeña, más o menos a los siete años de edad, jugaba al marido y a la esposa con su primo Jack, en la cama grande de la abuela. Y ambos hacían todo para tener hijitos sin lograrlo. Nunca más volvió a ver a Jack ni quería verlo. Si era culpable, él también lo era." - p. 307), que optaba por la privación antes que por el exceso ("Soltera queda claro; virgen también [...] Ese día había hecho sus compras de 
comida: legumbres y frutas. Porque comer carne lo consideraba pecado."), promotora de una rigurosa moralidad ("Cuando pasaba por Picadilly Circle y veía a las mujeres esperando a los hombres en las esquinas, sólo le faltaba vomitar. ¡Además por dinero! Era demasiado para soportarlo.” - p. 307), que desconocía - y que prefería seguir desconociendo - su sexualidad y la del otro ("Se bañaba únicamente una vez por semana, el sábado. Para no ver su cuerpo desnudo, no se quitaba ni las bragas ni el sostén" - p. 308), parecía tener una vida perfecta, armoniosa y equilibrada consigo misma. Sin embargo, y a medida que avanza la narración, nos damos cuenta de que ese vida perfecta tenía sus matices y sus falencias, empezando por su inmensa soledad. Todo lo que representa al otro, ella lo vive como una amenaza, como algo que viene a contaminar su universo impoluto. Todos son inmorales, pecaminosos, sucios y corruptos.

Hasta que una noche llega Ixtlán a su vida. Este ser enigmático y prácticamente imposible de ser definido, está cargado de símbolos. Por un lado, proviene de Saturno. Saturno, en la tradición romana, es el dios de los extremos (¿indicio que anticipa el final?), a la vez, su nombre proviene de la tradición aborigen mexicana. Se comunica con Ruth en sánscrito, una de las lenguas indoeuropeas antiguas más tempranamente documentada y que hoy en día sólo se utiliza como lengua litúrgica o vehicular de cultura. Es decir, en él se funden orígenes y características de culturas y tradiciones diversas y contrapuestas. Además, está cubierto con un manto de color morado, color de la pasión. Este color se repite en varios elementos del texto (Ruth es pelirroja y cultiva geranios rojos), tal vez para indicar que la pasión llegará a la vida de Ruth para quedarse...

Luego del encuentro sexual con Ixtlán, Ruth pasará a hacer todo lo que no hacía antes, comer carne, beber alcohol, acostarse relajadamente en el pasto con las piernas abiertas, etc. Pero sentía que no era suficiente, que necesitaba desahogarse de otra manera y empieza a acostarse con otros hombres. El haber conocido a Ixtlán le permitió conocer el erotismo y conocerse a sí misma a todo nivel. Y ese inicio, ese despertase a los placeres mundanos, irá en crescendo, sin límite ni barrera alguna, incluso tomando la figura de la prostitución, actividad condenada social y moralmente desde diversos y antagónicos sectores de la sociedad: "Iría a quedarse en las calles y llevar hombres a su cuarto. Como era buena en la cama, le pagarían muy bien” (p. 313). Ruth ya no sabe de prejuicios, de moral y tabúes. Y esa transformación se plasma en el 
lenguaje, como bien sabe hacer Lispector en todos sus textos. El cambio de tono, la transformación en el registro, es fundamental en este relato porque acompaña la evolución del personaje: de un lenguaje armonioso, pulcro y correcto se pasa a uno más mundano, más sucio, más enérgico, espontáneo y visceral:

¡Basta de mecanografía! ¡Usted no me venga con otro de sus fingimientos! ¿Quiere saber una cosa? ¡Acuéstese conmigo en la cama, desgraciado!” [...] Estaba casado con una mujer pálida e insignificante, Joan, y tenía una hija anémica, Lucy. "Lo vas a disfrutar conmigo, hijo de perra. (p. 313-314)

Llegado este punto, entendemos el nombre del cuento y la importancia de los símbolos que lo atraviesan.

Por supuesto, podemos preguntarnos si esta metamorfosis no fue sólo un cambio de opuestos, de extremos, si el estereotipo inicial no ha sido reemplazado por otro estereotipo antagónico, si hay liberación en este cambio. Sin embargo, más que detenernos en este aspecto, me parece importante destacar que una vez más, Lispector presenta la transformación, el proceso, proceso íntimamente ligado al deseo y su discurrir. La sexualidad parece ser el impulso que lleva a los personajes de Clarice a conocer y conocerse, a ser pura performatividad. En términos de Earl Fitz:

What Lispector consistently presents, then, is a narrative world in which sexuality, regardless of the form or expression it takes, is a powerful, potentially life-transforming force, one that is ignored or repressed only at a great risk to our well-being. (2001, p. 64)

Totalmente de acuerdo con lo que sostiene Fitz, considero necesario resaltar que en la obra de Lispector la sexualidad es una fuerza transformadora en la existencia humana, es el acto que conecta el lenguaje con la existencia, que permite el acceso al conocimiento y el abandono del nivel de la ignorancia.

Otro cuento que podríamos analizar desde el mismo ángulo es "Plaza Mauá". Plaza Mauá es otra zona de prostitución en Brasil y, al igual que Algarve y Picadilly Circus, otro espacio donde circula el erotismo, el deseo y por lo tanto, otro espacio marginal opuesto a lo céntrico, lo hegemónico, lo bien visto. ${ }^{9}$ Este relato, tiene como

\footnotetext{
${ }^{9}$ Para sostener esto me baso en la caracterización que Néstor Perlongher establece para estudiar los centros de prostitución masculina en Brasil. Cito: "Algunos de estos circuitos operan, en verdad, contenidos o sumergidos en los tránsitos o circulaciones más globales. Trataríase, mejor, de ciertos funcionamientos que, aunque amarrados a máquinas más genéricas y totalizantes, no dejan de mantener
} 
protagonista a Luisa, cuyo apodo en el cabaret es Carla. Este primer movimiento de desdoblamiento y de juego de espejos se reproducirá a lo largo del texto en distintas situaciones y por diversos motivos. En el segundo párrafo, se nos deja bien en claro que Luisa vive fingiendo: finge en el cabaret y finge con su marido ("Y Carla 'trabajaba' de dos maneras: bailando medio desnuda y engañando al marido"; "Recibía una comisión por cada botella de bebida. Escogía la más cara. Y fingía beber: no era de alcohol.”-p. 349-350); su vida está marcada por la máscara, por la simulación, por la performance, por el disfraz. Por supuesto, no tenemos que dejar de tener en cuenta que la simulación es una característica intrínseca de la prostitución: la/el prostituta/o simula que su cliente le agrada, el cliente simula que el acto sexual y el acto de seducción no tienen su origen en la transacción comercial. Además, es el mundo de la apariencia per se: todos se exhiben como en una vitrina, lo exterior es la virtud por excelencia. Tomemos las propias palabras del cuento para ejemplificar:

Hacía que el cliente se emborrachara y gastara. Era tedioso conversar con ellos. Éstos la acariciaban, pasaban la mano por sus mínimos senos. Y ella con una bikini rutilante. Preciosa. De vez en cuando dormía con algún cliente. Agarraba el dinero, lo guardaba bien guardadito en el sujetador y al día siguiente se iba a comprar ropa. Tenía ropa para dar y tomar. (p. 350)

Pero Carla no era la única que se destacaba en el Erótica. También estaba Celsito (o Moleirao en el mundo del cabaret). Lispector la describe como "un hombre que no era hombre" y como un "travesti de éxito" al que "los marineros de la plaza Mauá adoraban”. Celsito, escapa en muchos aspectos a los patrones hegemónicos culturales, sociales y de género. La podríamos considerar como un sujeto con género incoherente o discontinuo, si tomamos la teoría deconstructiva de Judith Butler (1999). Según esta autora, estos son "seres que parecen ser personas pero que no se ajustan a las normas de género culturalmente inteligibles mediante las cuales se definen las personas" (p. 50). Es decir, estos sujetos cuestionan las categorías, las matrices mediante las cuales los sujetos se vuelven inteligibles y, por lo tanto, susceptibles de ser

con relación al cuerpo social normalizado un guiño de inquietante extrañeza, de relativa exterioridad. La práctica social (o, mejor, microsocial) de la prostitución virial aparece como resultante de uno de esos encuentros [...] En esa búsqueda una diversidad de dispositivos sociales entra en acción. El deseo vehiculizado y al mismo tiempo reconvertido por el dinero, obtiene una suerte de reverso de las grandes oposiciones binarias que atraviesas y segmentan el cuerpo social: oposiciones de clase (rico/pobre), de edad (joven/viejo), de género (macho/marica), intensificando las diferencias en la producción del goce." (PERLONGHER, 1997, p. 45 y 46) 
reconocidos, jurídica, social y culturalmente. La matriz hegemónica en esta sociedad es la matriz heterosexual que configura el tipo de relaciones y prácticas sociales y de género que son aceptadas y, por lo tanto, consideradas "normales". Celsito al travestirse cuestiona esas categorías pero también las cuestiona al formar una familia: "Celsito había adoptado a una niñita de cuatro años. Era para ella una verdadera madre. Dormía poco para cuidar a la niña. A ésta no le faltaba nada: tenía todo lo mejor y de lo bueno" (p. 351).

Por supuesto, y a pesar de que el narrador se encarga de aclarar que Carla y Moleirao no eran rivales, sus vidas contrastan y se oponen en todo sentido. Luisa es una "verdadera mujer" pero tenía "mínimos senos". Celsito era "un hombre que no era hombre" pero que "de tanto tomar hormonas había adquirido un facsímil de senos". Moleirao cuida a su hija en cada detalle y quiere para ella un futuro feliz, Carla no tenía hijos y apenas cuidaba de su gato siamés. Moleirao desempeñaba felizmente sus tareas de madre y de ama de casa, Carla apenas si quería pasar tiempo en su hogar y atender a su esposo.

Esta dupla armoniosa, deja de serlo en el momento en que Carla danza con un hombre que Celsito codicia, y al terminar, ella le comenta qué lindo había sido bailar con "un hombre de verdad". A partir de allí, Celsito, que entiende la indirecta, cuestiona cuán verdadera mujer es ella. Y como si quisieran ejemplificar en sus diálogos cada uno de los argumentos que un entendido en el tema del género podría dar, empiezan a cruzar distintos criterios y "pruebas" de ese supuesto "verdadero género" que cada una sostiene tener.

En principio, uno estaría tentado a decir que este relato en muchos aspectos reproduce las estructuras y las matrices de género. Sin embargo, creo vislumbrar en él un cuestionamiento a ellas por lo que desarrollamos anteriormente y porque se plantea la idea de que no hay un parámetro único a partir del cual definir la identidad de género y porque se propone la idea de un género no esencial ni original, determinado por el carácter biológico. Es decir, la propuesta sería abrir el interrogante y hacer caer la idea de que a determinada característica biológico-sexual le corresponde unívocamente determinada práctica, deseo o género. ${ }^{10}$ Tanto Carla como Celsito cuestionan la idea de

\footnotetext{
${ }^{10}$ En términos de Judith Butler (p. 50 y 59): "Los géneros “inteligibles” son aquellos que en algún sentido instituyen y mantienen relaciones de coherencia y continuidad entre sexo, género, práctica sexual y deseo. En otras palabras, los fantasmas de discontinuidad e incoherencia, concebibles sólo en relación con las
} 
que a determinada genitalidad corresponde determinada práctica: Carla porque poco responde al modelo hegemónico de madre, esposa y ama de casa y Celsito porque toma esos modelos siendo biológicamente hombre. Finalmente, podemos decir que el rango axiológico queda delimitado: identidades de género que de un modo u otro se desvían de la norma dominante, presentados por un narrador en tercera persona lo suficientemente omnisciente como para saber cómo se sienten estas protagonistas con respectos a ese desvío.

\section{Mujeres que devienen en y por el Otro}

En muchísimos textos de Clarice Lispector podemos ver la importancia del otro para llegar a conocerse a uno mismo y para alcanzar la epifanía, el momento que nos revelará la profundidad de la existencia humana.

En "Encarnación involuntaria", una primera persona protagonista nos confiesa, a través de un monólogo interior, su más íntima e inmanejable obsesión: encarnarse en el otro, volverse el otro para comprenderlo y para comprenderse. Prácticamente como un sonámbulo al llegar la noche, esta mujer se deja llevar por el otro y su máscara para enmascararse ella misma, fascinándose por el mundo ajeno (y prácticamente sin medir las consecuencias de esa fascinación). Así, al encontrarse por ejemplo con una misionera, ella se siente misionera, toma su máscara, su disfraz y se produce su metamorfosis y desdoblamiento: "Porque sobre todo me he vuelto moral. Mientras que al subir al avión era saludablemente amoral. ¡Era, no: soy!, me grito rebelándome contra los prejuicios de la misionera."

La encarnación la lleva a un planteo existencial: cuándo somos realmente nosotros y cuánto hay del otro en nosotros mismos ("Tal vez sólo haya sido propia más que en el momento de nacer; y por lo demás haya estado hecha de reencarnaciones. Pero no: soy una persona." - p. 296). Lispector pone sobre la mesa una serie de interrogantes que hacen de este relato un texto de fuerte contenido filosófico-

normas existentes de continuidad y coherencia, son prohibidos y producidos constantemente por las mismas leyes que intentan establecer líneas de conexión causales significativas entre sexo biológico, géneros culturalmente constituidos y la "expresión" o "efecto" de ambos en la manifestación del deseo sexual a través de la práctica sexual [...] Esta concepción del género presupone no sólo una relación causal entre sexo, género y deseo, sino que también sugiere que el deseo refleja o expresa al género y que el género refleja o expresa al deseo." 
existencial: ¿somos o estamos siempre construyendo ese somos?, ¿somos únicos o siempre somos el producto del contacto con el otro?

El cuento se cierra con una encarnación que no resultó. La mujer se encuentra durante un viaje con una prostituta, pero no logra que los hombres la vean como tal ni nunca llega a tomar su máscara, tal vez porque no se dejó llevar por esa fuerza sin intención sino que intentó forzar la encarnación (el tomar la máscara del otro siempre es un acto inconsciente e involuntario, parece querer decirnos aquí Clarice...).

En "La salida del tren”, Doña María Rita Alvarenga Chagas Souza Melo, una anciana, se encuentra con Ángela Pralini, una mujer madura pero notoriamente más joven que la primera. Al sentarse una frente a la otra en un vagón de un tren, comienza un diálogo interno y externo entre las protagonistas y un rizomático juego de espejos. A partir de ciertos equívocos y malentendidos, ambas dejarán atrás sus prejuicios, sus complejas y antiguas estructuras para dejarse llevar por el mundo del otro, hasta llegar, cada una, a una epifanía profana, una comprensión de su propio universo. Como una puesta en abismo, se escuchan antes de la partida del tren distintas músicas que se van fundiendo, de orígenes y características distintas: "Del otro vagón se oía a un grupo de bandeirantes que cantaban Brasil agudamente. Afortunadamente, era en el otro vagón. La música de la radio del chico se entrecruzaba con la música del otro, que estaba escuchando a Edith Piaf cantando J'attendrai" (p. 380). Del mismo modo, las historias de estas mujeres, sus pensamientos, sus devenires, se entremezclarán hasta llevarlas por caminos nunca esperados.

Por un lado, María Rita va abandonando paulatinamente su amargura. Por otro, Ángela siente que se deja llevar sin rumbo fijo, se siente corriéndose de ese centro que tanto la hostigaba, centro construido por Eduardo (y su mundo falocentrista). Ambas carecen de un lugar propio, de un lugar o un rol fijo o determinado en sus familias ("Soy como un paquete que se entrega de mano en mano", piensa María Rita; "Nadie sabe dónde estoy" y aclara el narrador sobre Ángela "y eso la asustaba un poco, ella era una fugitiva" (p. 380-381) ${ }^{11}$.

${ }^{11}$ Debemos destacar antes de seguir avanzando en el análisis de este relato, que el narrador en tercera persona, se funde aquí con la voz, con el fluir de la conciencia de las protagonistas, utilizando frecuentemente el discurso indirecto libre, característica que algunos teóricos relacionan con una literatura postestructuralista: "There is the importance that is attached to the acts of writing (best understood in Lispector's case as écriture, a term Ann Banfield links to the use of "style indirecte libre", or free indirect discourse, a narrative mode extensively cultivated by Lispector) and reading, activities that, by virtue of their ability to unlock and mix the various levels of meaning that a text can generate for us, are 
María Rita se sabe más rica que todos aquellos que comparten con ella el tren pero también se sabe más miserable, más terriblemente ordinaria, por las relaciones frívolas y carentes de afecto que la unen a su familia:

Soy vieja pero soy rica, más rica que todos aquí en el vagón. Soy rica, soy rica [...] Soy muy rica, no soy una vieja cualquiera." Pero sabía, ah, sabía bien que era una vieja cualquiera, una viejita asustada por las menores cosas. Se acordó de sí misma, el día entero sola en su mecedora, sola con los criados, mientras la hija public relations, pasaba el día fuera, no llegaba hasta las ocho de la noche, y ni siquiera le daba un beso. (p. 381)

Además de retomar aquí el motivo de la frívola y distinta vida de la clase alta, Lispector explora el universo relegado de la ancianidad. Los mayores vistos como un peso, como una carga para una sociedad que evita a toda costa perder los supuestos beneficios de la juventud. La ancianidad vista como el momento del sinsentido, de la nula productividad, en un mundo signado por la lógica capitalista de la actividad sin contemplación, de la actividad como un fin en sí mismo:

Doña María Rita pensaba: cuando se hizo vieja comenzó a desaparecer para los otros, sólo la veían de reojo. Vejez: momento supremo [...] Pero nunca le pasó por la cabeza que era una solitaria. Sólo que no tenía que hacer. Era un ocio forzado que en ciertos momentos se tornaba punzante: no tenía nada que hacer en el mundo salvo vivir. (p. 384)

A su vez, Ángela, que se sabe perdida en una red de dominados-dominantes, busca su identidad, la certeza de su ser en la madurez de su compañera de vagón: "Soy lo que soy y no lo que piensas que soy. La prueba de quién soy es esta salida del tren. Mi prueba también es doña María Rita, ahí enfrente. ¿Prueba de qué? Sí. Ella ya tuvo su plenitud" (p. 384).

Para Doña Rita el viaje es prueba de que a pesar de su vejez sigue siendo autónoma, capaz de desenvolverse por sí misma; para Ángela el viaje es prueba de su independencia con respecto a Eduardo y su mundo dominante, a pesar de que en esa separación se sabe vacía, incompleta (Ángela compara el vacío que siente por la separación con lo que le "ocurre a las mujeres a quienes les extraen el útero y los ovarios"). Podríamos decir entonces que el desplazamiento físico, es un desplazamiento

demonstrative not only for postestructural theory but of its connection to reader-response theory." (FITZ, 2001, p. 6) 
también de identidades, desplazamiento que implica un dejar de ser lo que los demás quieren que se sea, para empezar a ser lo que uno realmente quiere ser o, mejor aún, ser un devenir, un dejarse llevar. Este desplazamiento identitario se vuelca en el lenguaje en la proliferación de gerundios a los largo del texto que nos dan una idea de fluir, de camino, y no de punto de llegada o esencialismo:

Un diálogo que sostenía consigo misma:

— ¿Estás haciendo algo?

- Sí, claro: estoy siendo triste.

¿ ¿No te molesta estar sola?

-No; pienso.

A veces no pensaba. A veces se quedaba solo siendo. No necesitaba hacer. Ser era ya un hacer. (p. 386)

A su vez, y como si la autora quisiera en el cuento concentrar un ir en contra de todo lo que establecido, de todo lo hegemónico, reivindica lo menor, lo desechado, lo estigmatizado desde el saber y la razón:

- reivindica la Edad Media, tan vapuleada frente a otros momentos históricos: “¿cómo se las arreglaban en la Edad Media sin teléfono y sin avión? Misterio. Edad Media, yo te adoro con tus nubes negras y cargadas que desembocaron en el Renacimiento luminoso y fresco."

- $\quad$ reivindica lo popular por sobre lo intelectual:

yo estaba cansada de intentar ser lo que tú creías que soy. Tengo un lado malo [...] y en ese lado fuerte yo soy una vaca, soy una yegua libre que patea en el suelo, soy una mujer de la calle, soy vagabunda y no una 'letrada'. Sé que soy inteligente y que a veces escondo eso para no ofender a los otros con mi inteligencia, yo que soy una inconsciente. (p. 387)

- $\quad$ reivindica los géneros considerados menores: "Soy vulgar, Eduardo, y tienes que saber que me gusta leer historias de folletín [...] Selecciones del Reader's Digest, que ella a veces leía a escondidas de Eduardo.” (p. 388, 390)

- $\quad$ el caos frente al orden y la estructura: "La coherencia, no la quiero más. La coherencia es mutilación. Quiero el desorden. Sólo adivino a través de una vehemente incoherencia." (p. 389) 
- $\quad$ reivindica lo escatológico, lo natural, las necesidades básicas, frente a lo artificioso, las necesidades creadas:

Ella se había transformado en una mujer urgente [...] Quiero comer, Eduardo, tengo hambre, Eduardo, hambre de mucha comida. ¡Soy orgánica! [...] La vida que llevaba con Eduardo tenía olor a farmacia nueva recién pintada. Ella prefería el olor vivo del estiércol por más repugnante que fuera. (p. 389-390)

- $\quad$ el vacío frente a la presencia inerte y sin sentido: "Después, en seguida, vació su pensamiento. Y era tranquilamente nada. Existía apenas. Era bueno así, muy bueno incluso. Inmersiones en la nada.” (p. 390)

Y como broche de oro, Lispector se incluye metaficcionalmente en el relato, como una puesta en abismo, eliminando toda barrera entre la ficción y la realidad o, mejor dicho, uniendo esa dicotomía en un infinito que se funde, que no tiene límites ni fronteras:

La vieja era anónima como una gallina, como había dicho una tal Clarice, hablando de una vieja desvergonzada, enamorada de Roberto Carlos. Esa Clarice incomodaba. Hacía gritar a la vieja: ¡tiene! ¡que! ¡haber! ¡una! ¡puerta! ¡de saliiiiiiiiida! y la había. [...] Ángela se dijo como si se mordiera rabiosamente: tiene que haber una puerta de salida. Tanto para mí como para Doña Rita. (p. 391)

Ángela y María Rita se encontraron casualmente en un viaje de tren y casualmente también tomaron conciencia de sí mismas y de la necesidad del otro para ser o, en otras palabras, para seguir siendo. La salida del tren pone énfasis en la partida, en el viaje, en el desplazamiento, pero no en la llegada (de hecho es más que llamativo y significativo el poco espacio que se da al momento de la despedida, de la llegada y de la separación). Lispector parace querer decirnos que lo importante es ese devenir, ese dejarse ir, ese correrse de lo instituido, de los roles que nos han (y nos hemos) impuesto.

Y sí. Clarice incomoda porque rompe todo parámetro, porque deconstruye, porque cuestiona, porque desenmascara, porque desesencializa. Porque estas mujeres nunca se saben acabadas, completas, sino que valientemente se interrogan y se replantean su vida y su identidad.

\section{Seres fuera de género}


En primer lugar tres era los sexos de las personas, no dos, como ahora masculino $y$ femenino, sino que habia, además, un tercero que participaba de estos dos, cuyo nombre sobrevive todavía, aunque él mismo ha desaparecido. El andrógino, en efecto, era entonces una cosa sola en cuanto a forma y nombre, que participaba de uno y de otro, de lo masculino y de lo femenino, pero que ahora no es sino un nombre que yace en la ignominia.

Platón, Banquete

Pasemos por último a analizar el cuento “¿Dónde estuviste de noche?”, a mi parecer, uno de los cuentos más deconstructivos de Clarice Lispector.

El relato tiene como último epígrafe una cita de William Hurvey en que se anticipa que lo que se va a plantear va a ser novedoso, vanguardista, tan novedoso que tal vez genere rechazo e indignación. Como si Lispector tuviese conciencia de lo rupturista de su literatura y de su propuesta ficcional. Lo que más parece destacarse al comienzo, es la presentación de este personaje indefinido, de características ambivalentes que quedan ya planteadas en la forma con que Lispector la/lo denomina: Él-ella. Este ser que el narrador mismo define como andrógino, es tan increíblemente bella/o que todos lo desean, lo evocan y lo veneran. Y ese "todos" abarca todo tipo de seres y géneros, convirtiendo este texto en un relato más que cercano a lo fantástico, a lo onírico: "Ellos eran al revés del Bien. Subían la montaña mezclando hombres, mujeres, duendes, gnomos y enanos, como dioses extintos" (p. 403).

En ese universo imposible de categorizar, no hay mediación simbólica, todo es preconsciente o preedípico en términos psicoanalíticos ("En fin, en fin, no había símbolo, la "cosa" era. La cosa orgiástica. Los que subían estaban al borde de la verdad." - p. 403); todo se plantea como una zona híbrida que funde y conjuga extremos comúnmente irreconciliables ("Pero después la niñita, también se carcajeó llorando, mezclando lágrimas de risa y de espanto [...] "Soy Jesús, soy judío”, gritaba en silencio el judío pobre [...] La latencia pulsaba leve, ritmada, ininterrumpida." - p.403405 ); se atribuyen características humanas a lo animal y viceversa ("Un perro se reía a carcajadas en la oscuridad.”- p. 403 ) y el tiempo es indefinido (“¿Qué hora sería? Nadie podía vivir en el tiempo, el tiempo era indirecto y por su propia naturaleza siempre inalcanzable." - p. 404).

Por supuesto, Él-ella es el punto álgido de la deconstrucción del relato. En primer lugar, porque como dijimos anteriormente, borra toda marca definida y única de 
género, por su nombre y porque a veces se refiere a este ser en femenino ("Y miraba a aquella sempiterna Viuda, la gran Solitaria que fascinaba a todos" - p. 404) y a veces en masculino ("El Mal-aventurado"). Está cubierta/o por un manto morado (color de la pasión y el deseo como ya vimos en "Miss Algrave"); todos la/lo quieren imitar sin lograrlo; es pura metamorfosis ("Entonces ellos comenzaron a balbucear hacia adentro, porque Ella-él era caústica y no quería que se perturbaran los unos a los otros en su lenta metamorfosis [...] En noches sin luna Ella-él se transformaba en lechuza." - p.404, 406 ) y el narrador destaca su carencia de toda nominación ("Porque nadie podía dejarse poseer por Aquel-aquella-sin-nombre." - p. 406). Asimismo, es importante destacar que cada tanto aparece un yo inidentificable ("Yo despreciaba los preceptos de los sabios que aconsejan la moderación y la pobreza del alma.”, ¿quién enuncia esa frase? ¿a quién debemos atribuírsela?, ¿es la conciencia de Él-ella?” - p. 406); un yo que se sabe huidizo, imposible de delimitar ("Estoy vigilante en el mundo: de noche vivo y de día duermo, me esquivo. Yo, con olfato de perro, orgiástico.") ${ }^{12}$. En términos de Fitz (2001, p. 84):

\begin{abstract}
By refusing to allow the reader to know the character only in terms of the "He-she" form [...] Lispector's text deliberatly "deconstructs itself denying the reader the luxury of either/or" thinking and forcing us to understand this character not in terms of being either female or male dominated but in terms of being in flux, of being a hybrid character who is constantly evolving, conciously and unconunciously (via Lispector's use of free indirect discourse)
\end{abstract}

12 A mi entender podemos ver a este personaje como un personaje queer. Abordaré aquí algunas cuestiones referidas a ese término que considero necesarias para poder iniciar el análisis posterior. En primer lugar, queer es un concepto (si es que así podemos llamarlo) que es indefinible por sus propias características y por su propia naturaleza. En su origen, es un término que circulaba en la calle, en el sentido común, para expresar aquello que es "raro" o "torcido". Hacia fines del siglo XX se recicla ese término como respuesta a las limitaciones liberacionistas e identitarias de la "época gay". De este modo, se dejan de lado las teorías esencialistas sobre la identidad y se comienza a pensar el género a partir de la diferencia y no a partir de rótulos ni encasillamientos. Este término se irá introduciendo en todos los ámbitos y será el posestructuralismo francés el que le dará cuerpo y fuerza al movimiento y a la teoría queer.

Si seguimos las ideas de Annemarie Jagose, podemos pensar lo queer bajo dos facetas fundamentales: la primera, como amalgama de procesos identificatorios y la segunda, como modelo de teoría a posteriori. Por supuesto, siempre pensando que lo queer no tiene una esencia, ni un grupo de características específicas, sino que es un objeto de estudio intrínsecamente ambiguo y relacional que escapa a toda clasificación o caracterización porque significa siempre algo distinto en contextos diversos. En palabras de la propia autora: "Given the extent of its commitment to denaturalisation, queer itself can have neither a foundational logic nor a consistent set of characteristics [...] This fundamental indeterminacy makes queer a difficult object of study; always ambiguous, always relational [...] queer evades programmatic description, because it is differently valued in different contexts" (Jagose, 1996, p. 96 y ss.).

Finalmente, me parece interesante destacar, apoyándome en la misma autora, que lo queer siempre mantiene una relación de resistencia hacia todo lo que constituye la "normalidad". 
defining and redifining itself in terms od the potentialities and limitations of its lenguage system.

En este ritual al revés, todo es contraste, inversión, contradicción, ausencia de límites definidos: se cruza lo humano con lo animal, lo espiritual con lo carnal, lo lujurioso y pecaminoso con lo elevado, lo mortal con lo inmortal, lo sagrado con lo profano. ${ }^{13}$ Todos los deseos, ambiciones y excesos aparecen representados en el cuento. En un gesto típicamente gótico-romántico se atribuye al día la ceguera y a la noche lo verdadero, lo revelador:

Él-ella les contó, dentro de sus cerebros [...] lo que le ocurría a una persona cuando no atendía la llamada de la noche: le ocurría que en la ceguera de la luz del día la persona vivía en carne abierta y con los ojos ofuscados por el pecado de la luz, vivía sin anestesia el terror de estar vivo [...] Y el día siempre comienza. El día bruto. La luz era maléfica: se instauraba el enfantasmado día diario [...] He aquí lo que ocurre cuando alguien escoge, por miedo a la noche oscura, vivir en la superficial luz del día... (p. 407, 413414)

El ascenso nocturno y orgiástico tenía como fin experimentar supersensaciones que conlleva la idea por un lado de alcanzar el goce sin mesura y por el otro la idea de tomar un atajo para conseguir algo.

Al igual que en "El huevo y la gallina" y que en muchos otros cuentos de Clarice, este relato destaca lo monótono, lo rutinario y lo predeterminado de nuestra existencia. Aquí cada ser que se desplaza durante la noche busca encontrar lo que durante el día le es prohibido o inconcebible experimentar.

Lispector cierra este cuento con la ironía, el hermetismo y la genialidad que la caracteriza, haciéndose la misma pregunta que plantea el título, recordando aquella frase popular que desconfía de lo que el recién arribado ha hecho durante su aventura nocturna. Recordando que vivimos en un mundo que constantemente limita nuestros deseos, nuestra capacidad de ser únicos y originales, de escapar a toda matriz que intente estructurarnos, de ser nómades o líneas de fuga...

\footnotetext{
${ }^{13}$ No sé si será muy arriesgado ver en esta figura venerada una inversión o parodia de la figura mesiánica de Cristo. Invertida por lo andrógino, por el color de sus vestiduras, por el vínculo carnal y sexual que la/lo liga con sus seguidores, por el epíteto con el que se la/lo denomina en algunas partes ("El Malaventurado o Él-ella, frente a la adoración de los reyes y vasallos, brillaba como una iluminada águila gigantesca" - p. 404).
} 


\section{Concluyendo para no concluir}

Tanto el hombre como las gallinas tienen miserias y grandezas.

Clarice Lispector

El artículo intentó demostrar que era posible considerar la literatura de la escritora Clarice Lispector como una literatura menor en los términos que lo proponen Deleuze y Guattari.

En primer lugar, porque aparecen retratadas distintas minorías que por diversos motivos son excluidas, marginadas, relegadas o discriminadas en la sociedad imperante: mujeres alcohólicas, prostitutas, ancianas, travestis, pobres etc.

En segundo lugar, porque estos personajes cuestionan, socavan, desde distintos aspectos, en su devenir, los binarismos hegemónicos y dominantes con que se nos ha impuesto pensar, imaginar y representar nuestro mundo.

En tercer lugar, porque propone una revalorización y una resignificación del mundo deseante; es decir, Lispector contrapone al mundo racional y lógico una literatura rizomática, deconstructiva, caótica, que retoma y revaloriza lo que la sociedad descarta, que juega y experimenta con el lenguaje, con los usos y formas, con las voces, con el tiempo y el espacio. Por eso elegí cerrar el análisis con el cuento “¿Dónde estuviste de noche?", porque muchos aspectos que ya hemos enumerado acercan este cuento a una suerte de experimentación surrealista, a un universo onírico y deseante. Pero toda la literatura de Lispector se acerca al deseo en todos sus niveles y representaciones. Además, esta escritora, a través de numerosos recursos irónicos cuestiona, a través de las voces de los personajes o a través de la intromisión de sus narradores, este mundo marcado por la ausencia del deseo y signado por una fuerte doble moral falocentrista.

Es en este sentido (y creo por lo menos haberlo intentado) que esta monografía intentó recorrer los textos de Lispector como una cartografía deseante, intentando construir un mapa de otro Brasil: Brasil de devenires minoritarios - devenir mujer, devenir andrógino, devenir travesti, devenir, anciano, devenir animal -, de procesos de marginalización y minorización, de movilizaciones de sujetos "no garantizados", ininteligibles, en tentativas de fuga que recorren y agitan el cuerpo social. 
No tan casualmente, muchos de los cuentos elegidos tienen como protagonistas mujeres. Me pareció adecuado elegirlos por lo que estos cuentos proponen como devenir: devenir mujer pero también devenir minoritario o animal en tanto y en cuanto las mujeres, "únicos depositarios autorizados para devenir cuerpo sexuado" ocupan una posición minoritaria con relación al paradigma del hombre mayoritario - machista, blanco, adulto, heterosexual, cuerdo, padre de familia, habitante de las ciudades -" (PERLONGHER, 1997, p. 68).

Finalmente, me parece fundamental destacar que el desarrollo del trabajo permitió recorrer las tres características que Deleuze y Guattari atribuyen a una literatura menor: en la literatura de Lispector se hace un uso minoritario y desterritorializante de una lengua mayor al experimentar con el lenguaje a todo plano y nivel, el plano social inunda el plano individual y todo toma un valor colectivo, social y político al cuestionar y socavar los pilares del universo logocentrista. Lispector nunca se desenvolvió en lo fijo, en lo seguro, en lo correcto, en lo que agrada; por el contrario, y como decía en el cuento "La salida del tren", Lispector incomoda, cuestiona, interroga, deconstruye. Propone prácticamente infinitas maneras de ver y pensar lo que comúnmente se nos incita a pensar de manera unívoca y totalizante. Sus personajes nos muestran los matices, los bemoles de un mundo frívolo, calculador y racional, definido siempre desde extremos incuestionables. Son prueba fehaciente de que hay otra manera de ser, de percibir y de concebir. Son prueba de que un mundo que vuelva al deseo es posible. 


\section{REFERÊNCIAS}

ARFUCH, Leonor. Problemáticas de la identidad. In: Identidades, sujetos y subjetividades. Buenos Aires: Prometeo, 2005.

BUTLER, Judith. Sujetos de sexo/género/deseo. In: Feminismos literarios. Madrid: Arcos/libros, 1999.

DELEUZE, Guilles y GUATTARI, Félix. Rizoma. Valencia: Pre-Textos, 1997.

Kafka. Por una literatura menor. México: Era, 1978.

FITZ, Earl E. Sexuality and Being in the Postestructuralist Universe of Clarice

Lispector. The Différance of Desire. Austin: University of Texas Press, 2001.

HUMPHREY, Robert. EI fluir de la conciencia en la novela moderna. Santiago de Chile: Editorial Universitaria, 1969.

JAGOSE, Annamarie. Queer Theory. An Introduction. New York: University Press, 1996.

LISPECTOR, Clarice. Cuentos reunidos. Madrid: Siruela, 2008.

PERLONGHER, Néstor. Prosa Plebeya. Buenos Aires: Colihue, 1997.

PLATÓN. Banquete. In:___ Diálogos. t. III, Madrid: Gredos, 2000.

VOLOSHINOV, Valentín. El discurso en la vida y el discurso en la poesía. Revista Zvezda, 1926. 